\title{
Psychotropic Drug Use: Between Healing and Enhancing the Mind
}

\author{
Toine Pieters $\cdot$ Stephen Snelders
}

Received: 12 September 2008 / Revised: 13 January 2009/Accepted: 16 January 2009 / Published online: 11 February 2009

(C) Springer Science + Business Media B.V. 2009

\begin{abstract}
The making and taking of psychotropic drugs, whether on medical prescription or as selfmedication, whether marketed by pharmaceutical companies or clamoured for by an anxious population, has been an integral part of the twentieth century. In this modern era of speed, uncertainty, pleasure and anguish the boundaries between healing and enhancing the mind by chemical means have been redefined. Long before Prozac would become a household name for an 'emotional aspirin' did consumers embrace the idea and practice of taking psychotropics not only to treat mental illness but also to make them feel better about living in a modern world. The Freudian promise that each individual can remake him- or herself in the pursuit of health and happiness was helpful in promoting and legitimizing the idea and practice of seeking wellness on prescription. We will argue that the modern consumer-driven political culture of medicine will continue to transverse the boundaries of therapy and enhancement of the mind into the largely unexplored territories of human cognition and behaviour. However exciting, this endeavour will come at the cost of further widening the problem
\end{abstract}

T. Pieters $(\bowtie) \cdot$ S. Snelders

Department of Metamedica, VU medical centre, P.O. Box 7057, 1007 MB Amsterdam, The Netherlands e-mail: a.pieters@vumc.nl

T. Pieters

Division or Pharmacoepidemiology and Pharmacotherapy, University of Utrecht,

Utrecht, The Netherlands of iatrogenic addiction in the age of happiness pills as 'botox' for the mind.

Keywords History Psychotropics Enhancement . Cycle $\cdot$ Cosmetic $\cdot$ Addiction $\cdot$ Psychopharmacology

\section{Introduction}

In his bestselling 2001 novel The Corrections the American author Jonathan Franzen concocts a futuristic story about the arrival of a new generation of personality optimizers. "The action is effectively instantaneous. That's the glory of it...compared with up to 4 weeks for some of the dinosaurs they are still using...Go on Zoloft today and you're lucky to feel better a week from Friday" [1].

Despite still rising consumption figures of Zoloftand Prozac-like selective serotonin reuptake inhibitors the heydays of what has been labelled the antidepressant era are over. ${ }^{1}$ From the turn of the century the SSRI's have gradually passed in American, British and Dutch public perceptions from remarkably safe and effective medicines to allegedly dangerous and addictive drugs. In a similar fashion as Valium and Librium the SSRI's have been associated with an epidemic of iatrogenic addiction. This rather dramatic re-evaluation of what in the 1990s still counted as wonder drugs for the mind coincides with most of these drugs having run out of their patents [2-8].

\footnotetext{
${ }^{1}$ World wide it concerns a market of more than 25 billion \$ (8\% of the total global therapeutic drug market) with average yearly growth figures of about $10 \%$; IMS Health 2008.
} 
On the basis of the cyclical dynamics of the careers of psychotropic drugs it seems to be only a matter of time before the SSRI's will be replaced by a new generation of more sophisticated medicines with the promise of more instantaneous and selective mood-affecting effects. The marketing of this new generation of personalized prescription drugs will focus on the prospect of creating yet another horizon of healing and enhancing the mind. In doing so the 1932 vision of Aldous Huxley in Brave New World will once again be reiterated: pharmaceutical companies will provide us with first cure and then joy, peace, loving-kindness and beauty in a pill [9].

The making and taking of psychotropic drugs, whether on medical prescription or as self-medication, whether marketed by pharmaceutical companies or clamoured for by an anxious population, has been an integral part of the twentieth century $[10,11]$. In this modern era of speed, uncertainty, pleasure and anguish the boundaries between healing and enhancing the mind by chemical means have been redefined once and again $[12,13]$. Long before Prozac would become a household name for an 'emotional aspirin' did consumers embrace the idea and practice of taking psychotropics not to treat a mental illness but to make them feel better about living in a modern world.

In 1912 the German psychiatrist Max Seige pointed to the repetitious quality of the reports on psychotropic drugs in medical journals. In his view it always started with very optimistic reports about promising therapeutic results in a wide range of psychiatric conditions, soon followed by communications about the occurrence of side-effects or therapeutic claims that failed to materialize and gradually resulting in a reduction of the range of indications and uses [14]. Whether we focus on the introduction and use of the first synthetic psychotropic chloral at the end of the 19th century or the introduction and use of barbiturates like Veronal and Luminal at the beginning of the $20^{\text {th }}$ century Seige-like cycles of therapeutic optimism and disappointment manifests itself $[15,16]$. These early examples of modern wonder drugs for the mind became the first rehearsals of the post-world war II scenario seen with psychotropic drugs like Miltown, Valium or Prozac that acquired a great public following in the psychiatric home-care of the middle classes, seeking relief for the daily discomforts of mental ills and other nervous problems [10, 17-19].
In this article we will show how new diagnostic, therapeutic and recreational categories and the categorized patients and consumers have emerged hand in hand and changed as social and material conditions changed. Doctors, patients and other consumers had to learn how to use and cope with new generations of psychotropics between laboratory, bedside and the household; redefining the boundaries between healing and soothing the mind, and fulfilling fashionable desires of comfort, convenience and pleasure. The question is how and in what sense these boundaries have shifted over time and to what consequences? As part of the cyclical dynamics of psychotropic drug development and use we will point out a parallel spiralling of medically controlled legal ('on prescription') drug markets and criminally controlled illegal drug markets.

\section{The Emergence of a Mass-Market for Prescription-Only Psychotropics}

Hysteria was the most fashionable diagnosis for middle-class women in the latter part of the nineteenth century and neurasthenia would develop into the standard diagnosis for functional nervous disorders in the early twentieth century. Both conditions were characterized by overstrained, restless nerves and took on prominence against the background of a modern industrial society in rapid flux. Not only in psychiatric practice but within medicine as a whole, synthetic drugs like chloral hydrate and subsequently the barbiturates became widely used, the family doctor's familiar recourse in dealing with common symptoms from insomnia to anxiety and the vapours $[11,16,18]$.

The relative high pricing of the barbiturates did not prevent them from becoming the most popular hypnotics and sedatives of the first half of the twentieth century. This was not only due to the successful efforts of the pharmaceutical industry to project a modern scientific image on the barbiturates but also to the growing economic strength of the middle-classes, and to the expanding health insurance industry with its reimbursement of prescription drugs. Moreover, the enthusiastic acclaim for the barbiturates coincided with the growing disrepute of the opiates and the patent medicines associated with them. The International Opium Convention at The Hague (1912) 
and the passing of the Harrison Act in the United States (1915), followed by similar restrictive opiate legislation in other countries created a gap in family medicine cabinets. Doctors and lay consumers in search for psychoactive substances with sedative and hypnotic properties increasingly drifted towards the barbiturates. Barbiturate brand names like Veronal, Verpnal or Medinal (barbital) and Luminal (phenobarbital) and later on Seconal (secobarbital) and Amytal (amobarbital) became household words [20-23].

It would last until the 1930 s before the critical appraisal of the barbiturates as dangerous drugs could be heart in the public sphere with alarming media reports on the statistics of barbiturate deaths among the middle classes. In response the supply of barbiturates was increasingly restricted under different national drug acts, with Britain and Germany taking the lead. In both countries Veronal and subsequently Luminal became prescription-only drugs, which officially could be dispensed only by licensed pharmacists and chemists. The foundations were laid for the emergence of a new mass-market for prescriptiononly psycho-active medicines [23].

Whether in Amsterdam, Berlin, London or Washington sedatives, hypnotics and stimulants, available in dozens of formulae and brands, were lavishly supplied on medical prescription. The liberal supply on the licit market, however, did not prevent the emergence of an illicit market. By the end of the 1930s the American Food and Drug Administration (FDA) began to issue public warnings against the perceived parallel exponential growth of the volume of so-called legitimate use and the volume of socalled illicit abuse of barbiturates and amphetamines. The latter was attributed to abuse among youths and young adults and associated with an alarming increase in traffic accidents [19, 23].

But regardless the new wave of legislative concerns in the USA the Second World War triggered an enormous increase in the demand for psychotropics. The armies of servicemen returning home with barbiturate and amphetamine experiences and supplies found receptive ground among the anxious and traumatised population of the Western countries. And the post-war period of reconstruction and coldwar related stress and fears did far from ease off demand. Moreover, new career paths were explored. Penthotal and Amytal, for instance, began to make a name for themselves as "truth serum" not only within military quarters but also in the fields of forensic medicine and psychoanalysis [19, 23].

The war-related surge of demand was a probable factor in the persistent growth of the use of barbiturates and amphetamines. Another factor was the supply chain. US production capacity rose exponentially. In 1950 drug companies produced more than 25 barbiturate and 10 amphetamine pills for every American citizen (pop. 151,3 million). This quantity was claimed to be far beyond 'legitimate medical needs' and to match that of the opiates at the turn of the nineteenth century. Likewise there are strong indications that in Britain the supply of barbiturates and amphetamines lawfully manufactured or imported also greatly exceeded the requirements of what was called 'legitimate medical use'. The prescription-only alliance between pharmaceutical companies, government, doctors, patients and pharmacists led paradoxically to an overproduction and oversupply of upper and downer pills that disappeared into an illegal market. An American estimate was that half of the legitimate production was meant for the illicit market with its distribution channels through saloons, taxi drivers, and truck stops [19, 23].

Given increasing visibility by the rise of scientific medicine and marketing practices of industry, and used in contexts that were increasingly subjected to media attention, psychotropic drugs became important focal points of cultural mediation and imagination in medical and public spheres. The growing armoury of sedatives, hypnotics and stimulants were perceived as invigorating a healthy mind and making it more resistant against the demands of the increasing pace of modern urban life; the housewife's and white collar man's upper and/or downer friend. As such the use of synthetic psychotropics became endemic in the first part of the twentieth century and would continue to support the fabric of social life in an expanding postwar Western consumer culture.

The second world war further heightened a sense of the value of psychosomatic medicine. Psychiatrists had reported extensively about soldier's experiences that stress, fear, neurotic anxiety and the emotions in general could produce any number of physical ailments [24]. The popular media helped to spread the belief in the psychological nature of illness and encouraged ideas about the healing potential of Freudian psychoanalysis. Nowhere was the shift in the public perception of the diagnosis and therapy of 
mental illnesses so dramatic than in the United States. The post war promise of psychoanalysis was that it could change undesirable states of mind and forms of conduct into less undesirable or even desirable ones. Self-awareness was promoted as a means to the end of engendering a better and healthier self and a better society. With a kind of iatrogenic effect, the psychologization of health and illness resulted in the growth of the need for therapy and not only of the therapeutic talk variety. General practitioners began hearing from all sides that they needed to recognize concealed mental health problems and patients became much more willing to accept a diagnosis for a nervous illness, and a matching prescription for a psychotropic medication $[19,25,26]$.

According to historian Nicolas Rasmussen in the early 1950s American family doctors embraced amphetamines as psychiatric medications for their distressed and neurotic patients suffering from overstrained nerves [19]. The amphetamine stimulants were referred to as psychic energizers, cementing the notion that mood problems in terms of mild and minor depression with symptoms such as insomnia, anxiety and disturbance of appetite were both commonplace and easily treatable. As part of an eclectic and pragmatic medical practice upper (stimulants) and downer (sedatives and hypnotics) pills, and psychoanalytic approaches were eagerly combined to treat what was considered an epidemic of neurotic anxiety $[19,25]$.

The pharmaceutical industry was rather helpful in developing, producing and marketing pills that did the job of energizing and soothing in one. They started promoting a new flexible concept of mood depression, in which insufficiently vigorous pursuit of pleasure and material reward due to an inability to cope with a speedy and tense society was recognized as a medical problem [19]. As a treatment for this condition a combination of dexamphetamine and amylobarbitone, under the trade name Dexamyl, became extremely popular in America, Britain and the Netherlands alike [26].

\section{Towards a New Chemistry of the Mind}

In the post-war period a new generation of chemists and pharmacologists worked hand in hand with the pharmaceutical industry to improve the efficiency of the industrial screening programs for therapeutic drugs. From a technical point of view, companies developed in their laboratories increasingly sophisticated capacities to attach successively different side chains to a chemical nucleus and systematically map the pharmacological properties of the resulting large series of compounds. At the same time science-based direct marketing helped to create a buzz around new would-be wonder drugs for body and mind. The post-war international economic boom with its vibrant consumerism and consumer desire, in combination with the performance driven ideologies and cultures of the cold war strongly stimulated demand for medicines. In conjunction with the post-war beliefs in the continuation of breakthroughs in modern medicine this would bring about the culture of a pill for every ill in the 1960s [25-28].

The testing of the effects of the psychotropic compounds in academic and industrial laboratories was matched by the testing of individuals and groups in household, street or nightlife settings. Each user or group of users selected from the wide range of compounds and affects a few as valuable and interesting. In their urge for self-testing house-wives, business-men, workers and youth-subcultures (e.g. beatniks) alike all more or less freely explored new territories ranging from healing, tuning to enhancing the mind. At least, until these upper and downer pills came to be seen as a habit forming health risk and the growing problem of addiction on prescription was regarded as a social menace to society. But before this would materialize a new generation of psychotropics was ready to take off and spawn new cycles of promise and hope $[18,25,26]$.

The introduction of chlorpromazine (Thorazine/ Largactil) in the early 1950 s is widely acknowledged as marking the beginning of a major psychopharmacological revolution. Together with the drug reserpine chlorpromazine transformed the prospects for the treatment of mental illness and rejuvenated the materia medica for the mind. Both new medications had a powerful impact not only on the atmosphere in the asylums - from places of chronic unrest mental hospitals turned into peaceful care centres-but also on a growing therapeutic optimism in the consulting room of psychiatrists and general practitioners alike. Expectations ran high about the arrival of a new penicillin-like era of healing the mind [10, 29, 30]. Popular texts on this revolution in the neurosciences and psychopharmacology like Paul de Kruif's A man against Insanity (1957) or Robert S. de Ropp's Drugs and the Mind (1957) became bestsellers [29, 31]. 
Right from the beginning the pharmaceutical industry was most helpful in emphasizing the qualities of chlorpromazine (Largactil ${ }^{\circledR}$ ) and reserpine $\left(\right.$ Serpasil $\left.{ }^{\circledR}\right)$ as the first modern wonder drugs for the mind and differentiating them from the conventional sedatives. This is nicely reflected in some of the $1950 \mathrm{~s}$ drug ads. Whereas in the case of chlorpromazine Van Gogh's painting The round of the prisoners was used to promote its special relief producing effect, in the case of reserpine the image of a pill superimposed on a brain with the caption 'different from the barbiturates' served to underline the new combination between sedation and mental recovery. In order to capture this new therapeutic profile and distinguish it from sedation proper scientists would begin to label chlorpromazine and reserpine as major tranquillizers from 1956 onwards [10].

The differentiation of the 'new' tranquillizers was given impetus by the observation that both chlorpromazine and reserpine counteracted the psychosis induced by another new promising synthetic molecule, the hallucinogenic drug LSD. In suggesting a relationship between chemical and clinical psychosis this observation opened up a horizon of drugs with wondrous potential for brain research, psychiatry and psychotherapy. A horizon which in 1957 was still described as 'pharmaco-psychiatry' would become publicly known as 'chemistry of madness' by the end of the 1960's [10, 32].

Being the experimental tool par excellence because of its efficacy in extremely small dosages counting in micrograms, LSD paved the way for a productive alliance between the neurosciences, pharmacology, psychiatry and clinical epidemiology. This would turn the so-called 'neurotransmitter revolution in medicine' into an addictive form of brain medicine for scientists, doctors and consumers alike: the chemically transformable mind. The questions about the ability of restoring the balance between psyche and soma, which from the 1920s had been mainly articulated in a Freudian psychological sense, would in the following decades increasingly come to be defined in biological and chemical terms. Mental discovery was superimposed on mental recovery by chemical means.

The scientific claims of a chemical transformable mind appealed to the imagination of the avant-garde of the Beat Generation and were further popularised by the gurus of the Sixties counterculture. They spoke of unlimited possibilities for the transformation of mind and body, psyche and soma. The evolutionary jump towards a mental Superman seemed at hand with a revolutionary molecule such as LSD.

In the American context Aldous Huxley played an important role in advocating democratic access to the new generation of mind-altering substances. He and other authors publicly heralded the advances on the neuropharmacological frontier and promoted using psychotropic drugs for relieving poverty, monotony, pain and limitation [32].

The pharmaceutical industry was quick to capitalize on the success of the new miracle drugs for the mind. The major tranquilizers like chlorpromazine were portrayed in the mass-media as modern penicillin-like weapons which had created a revolution in the doctoring of madness. The marketers rapidly secured the name minor tranquillizer to position a new generation of hypnotics and sedatives as novel technologies of the self to strengthen self-consciousness and counter negative feelings like fear, guilt or shame that were associated with an epidemic of psychosomatic health problems. Most advertisements of minor tranquillizers repeated the mantra that in every patient and every illness the individual management of anxiety and tension is essential to recovery. In itself this kind of self-remaking message was far from new and mirrored the claims of psychoanalytic therapy. But the accompanying message of a chemical adjustment of the psychosomatic balance was new $[10,25]$. As part of this shifting message the boundaries between healing and soothing the mind, and fulfilling fashionable desires of comfort, convenience and pleasure would be redefined accordingly. And between medical and non-medical uses of psychotropics.

\section{Mother's Little Helpers}

Neurotic anxiety became the signature illness of the 1950s and 1960s. Psychoanalytic psychiatry helped to place anxiety in the public eye as a treatable condition, but the age of anxiety was shaped by the actions of many different social groups: from researchers, doctors, patients to journalist, politicians and drug salesmen. The latter, in particular, propagandized the symmetries of illness and remedy and thereby helped creating new notions of illness and cure. The drug companies jumped on the anxiety 
bandwagon and helped to forge a productive alliance between consumer demand, psychic anguish and medicine. With the aim of casting the widest possible net for potential customers drug advertisers tended to conflate psychosomatic illness from stomach aches to heart troubles with the familiar daily problems of frustrations with work, household or other activities and relationships. According to the historian David Herzberg the minor tranquilizers were presented as consumer goods that would bring comfort and convenience to consumers' psychic and emotional lives; the latest new personal technology for pursuing happiness and achieving the good life [25].

The successful marketing of Miltown/Equanil (meprobamate) set the stage for the 'happiness pills' era. Whereas the intense excitement in the late 1950s about Miltown as the first minor tranquillizer was for the greater part an Anglo-American affair, the introduction in 1960 of Librium by the Swiss pharmaceutical company Hoffmann-La Roche was global news. The black-green capsules with the benzodiazepine compound chlordiazepoxyde - synthesized in 1955 and trade named Librium - became available as medication for anxieties and tensions [23]. Librium promised to be an anxiolytic without the problems of dependence and overdosing associated with the first minor tranquillizer meprobamate (Miltown) and the conventional sedatives and hypnotics [18, 33, 34].

The extensive worldwide information campaign of Roche, directed at specialists and general practitioners alike, and the inflationary spiral of stories in the media about a new medicinal drug with miraculous calming effects in small doses and no manifest side-effects, turned Librium into an overnight sensation. The 1960 phrase in Life Magazine: "The drug that tames wild cats-What will it do for nervous women?" turned into a self-fulfilling prophecy. Roche set a new global marketing standard for blockbuster drugs. Not only did they decide in favour of a single brand name but they also chose to market an all-embracing revolutionary treatment concept; a comprehensible and practical system of symptom identification, diagnostics, mode of action and therapy. At the centre was the flexible and for both general practitioners and specialists understandable and manageable concept of chemically restoring the balance between body and mind; through a specific switcher mechanism, the so-called 'limbic system'. In print promotions Librium was portrayed as an instant limbic stabilizer 'whatever the diagnosis'.
But Librium was not presented as the one and only compound to make this new chemotherapeutic approach of nervous problems feasible. This cleared the way for the introduction of supplementary tranquillizers with different therapeutic profiles. And Roche led the way in 1963 by bringing out the more potent and anxiety specific benzodiazepine analogue diazepam under the trade name Valium [23, 35, 36].

Librium turned out to be only the prelude to the Valium frenzy or 'Valiummania' [37]. Marketed as the most potent safe and sane anxiolytic of the day the pill with the telltale ' $\mathrm{V}$ ' rapidly surpassed Librium as the best selling tranquillizer in Western countries. In 1965 Roche introduced yet another benzo, the sleeping-pill Mogadon (nitrazepam). This drug, in contrast to the 'traditional hypnotics' (i.e., the barbiturates), was claimed to be reliable and safe and did not lead to narcosis, coma, or death in case of an overdose. The British and American Roche advertisements brought home the message of the superiority of Mogadon in a rather candid way: "Some patients stay on barbiturates until the day they die..." [38].

With the fast growing popularity of the benzos the therapeutic areas in which they were applied seemed to multiply unchecked [23]. Sleeplessness, nervousness, overexertion, stomach and back pains, hypertension and heart problems, and even psychotic disorders such as schizophrenia and manic depression became indications for administration of members of the extending 'benzo-family'. They were touted as the answer to everything, including the 'normal' emotional reactions to life's everyday challenges. In Germany and the Netherlands the following aphorism became popular among physicians: 'Wenn man nicht weiss, wie, was, warum, dann gibt man immer Valium' (when you don't know how to treat your next patient then it is time for Valium) [39].

Doctors and patients alike eagerly sought out the new drugs. Fortune magazine announced that the US was on the verge of a "choose-your-mood-society" that would allow "essentially normal people" to cope with and overcome the everyday stresses of their lives [25]. Popular representations of tranquillizers as a pill for every ill mirrored the consumption statistics. From the early 1960s up to late 1970s Librium, Valium, Mogadon and other benzos led the drug list in Western countries. The benzo-family together with the limbic concept of therapeutic action beautifully suited the interaction between general practitioners 
and their distressed patients, the needs and expectations each brought to the short office visit; offering a little help in their pursuit of everyday happiness. This was in spite of the accumulation of reports on sideeffects, observed as early as 1961 by the American medical internist Leo Hollister: tolerance, dependence, drowsiness, reduced alertness and other reactions leading to traffic accidents [23].

The promise of a psychoactive magic bullet, with a controllable and specific effect on the chemistry of the brain, a 'peace-of-mind' pill, was kept neither by the benzodiazepines or LSD nor by any of the other new synthetic compounds. On the contrary, the chemical effects of the drugs on the mind turned out to be remarkably non-specific and addictive. Apart from medical side-effects, cultural and social 'side effects' became manifest.

In 1966 when the psychologist Leslie Farber wrote his essay "ours is the addicted society" the Rolling Stones produced their classic hit 'Mother's Little Helper', epitomizing critique of middle-class tranquillizer addiction, alienation, and hypocrisy. Historian Susan Speaker shows how the critique on the making and taking of benzos in the United States was tied up with their becoming a symbolic focal point for articulating and addressing social anxieties and tensions but also expectations regarding "The Good Life" [37]. These expectations were redefined by the young American middle class baby boom generation, who lavished themselves with new spirits of peace and happiness during the 'Summer of Love' in 1967. While criticizing tranquillizer use of the elderly the hippie generation and their young heroes of popular music seemed saturated in drug allusions of yet another kind. The development of hippy and psychedelic movements co-evolved with an upsurge of LSD, cannabis and heroin use. With the promise of a spiritual enhancement of the mind the consumption of these drugs proliferated among the burgeoning youth cultures in Western countries.

The parallel spiralling of the medical and nonmedical consumption of psychotropics at the end of the 1960 s evoked politically consequential public opposition to both kinds of drug use. A rhetorical mix of direct harms to the middle class youth, anxieties about the collective future of a drug-infused society, perceived criminal behaviour of deviant groups, social costs of addiction, and the war on drugs provoked a worldwide backlash on psychotro- pic drug use. In the course of the 1970s (inter-) national narcotics laws were strengthened in an attempt to contain (i.e. benzodiazepines), restrict (i.e. amphetamines) or prohibit (i.e. cannabis, LSD or heroin) the consumption of psychotropics [21-23].

\section{Appetite for New Chemical Wonders for the Mind}

Regardless of the public portrayal and perception of most psychotropics as addictive and/or dangerous drugs the desire for and expectations of new molecules that might transform and enhance the chemistry of the mind continued to grow. The forceful antipsychiatry movement of the 1970s might have temporarily succeeded in halting the growth of the consumption of the so-called 'chemical straightjackets of conformity' (psychotropic medication on prescription) but by encouraging a shared drive for selfdevelopment and self-expression they also helped to further open up a horizon of achieving wellness by chemical means; giving impetus to a rehearsal of the era of happiness pills. In search for equality and appreciation of the 'other', the deviant, the protagonists of this critical movement did anything but halt the historical process of individual empowerment and a growing consciousness of self-control by any available means.

Setting out to make schizophrenia and mania intelligible, the antipsychiatry movement ended up not only destigmatizing madness and psychiatry, but making its language available and in some ways glorifying it. Paradoxically this not only helped to make madness more acceptable, but fed into a growing public interest in the pathological aspects of 'normal' people. Medical consumers showed an increased willingness to read unhappiness and malaise in terms of an expanding repertoire of inconvenient and undesirable symptoms that called for treatment. It helped turn everyone in a potential patient with a mental illness. This was not a passive patient but an assertive consumer participant who sought to educate him- or herself in order to negotiate more effectively a treatment with medical authority, or circumvent it altogether and seek for feelgood pills by any affordable way in the pursuit of happiness [10, 25, 35, 40].

The growing popularity of biological theories of mental disorders and rising expectations surrounding the bio-revolution in medicine wetted the appetite for 
new wonder drugs for the mind. In the mid-eighties, in the continuing search for happiness through chemistry, a new generation of youngsters began to experiment with the psychedelic MDMA under the universal brand-name ecstasy [41].

In the climate of neo-liberal, no-nonsense political economics of the Reagan and Thatcher era young urban professionals and students in London, New York and Amsterdam eagerly started to combine a new raving form of electronic dance music 'acid house' with the drug ecstasy. They eagerly distanced themselves from the heroin-associated, depressing no future ideology of the punk generation. With the new hug drug in their pockets hundreds and later on crowds of thousands of young people gathered in dodgy warehouses or disused industrial sites to dance away the night. The euphoric explosion of unlicensed ecstasy-fuelled rave parties in the summers of 1988 and 1989 was earmarked as the Second Summer of Love. The new optimistic dance culture drew parallels with the hedonism and freedom of the Summer of Love in San Francisco two decades earlier. Ecstasy served as illegal chemical means of mass 'self-enlightenment' between dusk and dawn; as such this and other drugs became a personal technology for constituting immediacy in delivering pleasures between street and medicine cabinet [41-43].

Apparently alarmed by media reports about serious health effects, the public fear of a distortion of public order and fuelled by the war on drugs politicians and government would eagerly climb down on the 'druginfected' house scene. Simultaneously, the social appetite for daily chemical 'self-control' - in terms of the immediate delivery of comforts and conveniences tuned to a specific state of mind or performance - on prescription was whetted by the promise and hope for once again a new generation of psychotropics. The desire for chemical forms of selfcontrol and self-betterment pervaded both medical and public domains. Once again enveloping and interfering spirals of medical and non-medical use of psychotropics became manifest.

The introduction and international circulation by the American Psychiatric Association of operational diagnostic criteria for psychiatric disorders in a series of manuals from the DSM-III in 1980 up to the DSMIVR in the 1990 s acted as an important catalyst of identifying and differentiating treatable forms of mental illness in the consulting room. The steady growth in the number of mental disorders in what became widely regarded as the 'diagnostic bible' of psychiatry helped medicalizing additional territories of human emotions, behaviour and cognition. Previously 'normal' human traits like shyness, aggression as antisocial behavior or attention deficit became a sickness. In the process the need and demand for medical treatments was stimulated $[4,44,50]$.

The pharmaceutical industry was first in recognizing the marketing potential of using the DSM as well as the rising tide of bio-optimism and the growing appetite for mind-altering pills. According to the historian Edward Shorter the FDA was rather helpful in setting rather ambiguous placebo guided testing standards for new drugs [44]. The American drug company Ely Lilly would lead the way. Its new antidepressant Prozac (fluoxetine) was launched in 1987. Prozac was presented as a revolution in the psychofarmacology of depression. Based on the latest scientific evidence a lowering of the brain neurotransmitter serotonin had been demonstrated in depression. And fluoxetine was claimed to selectively restore the serotonine levels in the brain back to normal. This relatively simple mechanistic model of mood levels and brain molecules promised a rather straightforward therapeutic trajectory in what was officially pronounced 'the decade of the brain'. By prescribing a compound like fluoxetine that lacked the nasty side-effects of the older tricyclic antidepressants or the addiction problems of the benzos doctors would be able to provide their patients with an all-in-one safe and effective depression and anxiety therapy [3].

The marketing message of once again a revolution in brain chemistry and the promise of a therapeutic break-through was picked up rather swiftly. The cycle of events following the introduction of Prozac even took Lilly's marketers by surprise. In celebrating Prozac as a wonder drug that effects miraculous changes in personality and social performancelowering inhibitions and increasing outgoing, confident behaviour-Peter Kramer's 'listening to Prozac' helped to create a worldwide pill taking hype. Kramer claimed that consumers had entered a new era of cosmetic psychopharmacology. The choice to become a Prozac consumer was presented as one's own choice of mood self-control and engineering wellness. It was not so much the therapeutic contract between a patient and a doctor that would make this mind pill do its work but the individual consumer's belief in the 
superior therapeutic power of a clean brain medicine $[25,45]$.

However fictional, this image of self choice and self repair had a great sex-appeal. Prozac started of as a promising vehicle for popularizing the new brain sciences and yet another generation of chemical consumer goods to achieve wellness on prescription. In 1994 Prozac was the second best selling medication world wide, just behind the drug for the treatment of ulcer problems, Zantac. Both Prozac and serotonin became household words - the epitome of modern interventions in the brain and of modern feel good tools. Moreover, Prozac marked the re-emergence of the pill for every ill culture that was heralded in the 1950s and 1960s. As far as the United States, the UK and the Netherlands are concerned the consumption of psychotropics on prescription regained its forceful growth pattern in the 1990 s, after a cyclical downturn in the late 1970s and 1980s [19, 23, 25, 39].

In the meantime depression prevalence rates coevolved and continued to rise. The age of anxiety and blaming society gave way to the age of depression and blaming your own brain. In a similar way as neurotic anxiety in the 1950s and 1960s depression has grown to epidemic proportions in modern, developed Western countries in particular. Within two decades the percentage of the population having depression that requires treatment has risen five fold on average: in 2009 more than $5 \%$ of the general population $[5,8]$.

Prozac's brand image of personal self repair and its apparent disregard of the therapeutic contract between a patient and a doctor fitted in rather well in the medicine on demand culture in the US. However, this very same brand image turned Prozac into an early loser on the fast growing Dutch market for antidepressants [45]. Dutch doctors preferred to prescribe therapeutic family members of Prozac like Paxil and Zoloft that did not pose a potential threat to their authority in the consulting room. Moreover, by the end of 1990s optimistic reports about promising therapeutic results in a wide range of psychiatric conditions were drown out by communications about the occurrence of side-effects or therapeutic claims that failed to materialize. As in the case of most consumer goods mass consumption deprived Prozac of its unique selling-point as a personal optimizer to tinker with your own 'neurochemical' identity. This romantic and personal connotation was lost as part of the consumerism on the medical market [25]. Contrary to Kramer's claims of the arrival of a new era of personal optimizers Prozac and the other members of the therapeutic group of SSRI's turned out to be rather unspecific middle-of-the-road feel good pills. The generic capacity of lifting moods in average consumers should earn these pills the label 'botox for the mind' in the age of happiness pills.

\section{Conclusion}

As we have shown throughout the twentieth century social and cultural factors, promise, hope, fashion and taboo have been of major influence on psychotropic use. This also holds for the familiarity with mental disorders, their recognition and acceptance, and ultimately the choice of treatment. What is recognized and accepted as mental illness and what is not? Are the consumers familiar with the possibilities of diagnosis and treatment? What expectations do they have of drug treatment? These aspects are influenced by publicity and media attention.

This is a dynamic process. Pharmaceutical companies have been of importance in this process. The drug marketers have continued to look for new markets by researching and influencing needs in the consultingrooms and translating them into treatment options. By information supply to physicians and more and more to potential consumers, drug companies have stimulated the consumption of psychotropics. Despite the importance that their impact may have, it still depends on the cooperation of physicians and consumers.

Depression, the drug company Pfizer once advertised, is the most democratic of all disorders. It can affect everyone at any moment, for shorter or longer duration, without a recognisable course. This kind of 'democratisation' of mental disorders and the application of psychotropic drugs, however, is not a unique selling point of the pharmaceutical industry. Exemplary in this case is the massive use of cognitive enhancing drugs (e.g. amphetamines) in the Second World War, the Cold War period and yet again in 2009 by both ill (e.a. ADHD sufferers) and healthy individuals (recently coined by Nature as 'professor's little helper') both on prescription and through other channels [46].

According to the vision of the future presented by the Dutch Health Council (Gezondheidsraad) in 2002 
human emotions, thoughts, and behaviour will become treatable and controllable. The health council predicted that a regular market for self-medication would develop outside of medicine, a market where consumers will be able to buy drugs to improve their mood or cognitive achievements. According to the council these future consumers should take responsibility, together with a 'platform against addiction' and the pharmaceutical industry, for security, reliability and handling the risk of addiction to the drugs [47]. The boundaries between treatment in a therapeutic sense, to get someone 'back to normal', and enhancement, of making someone better than he or she is, will continue to be redefined in this scenario.

However courageous the proposition of a public health focussed platform against addiction in a world dominated by a war against drugs, this vision disqualifies itself by proving historically uninformed. Despite historical changes in neuropsychopharmacological semantics and a progressive process of standardizing mental illnesses and pills we do not support fashionable views of a paradigm shift in consumer demand and behaviour regarding healing and enhancing the mind $[6,48,49]$. In our article we have argued that redefining boundaries between healing and enhancing the mind is not a new phenomenon in itself and the same holds for the practice of achieving wellness by chemical means. We have shown continuous dynamics of enveloping and interfering spirals of medical and non-medical uses of psychotropics as a means to healing and enhancing the mind. It is no surprise then that Huxley's subtle and challenging early warning of a dystopia of happiness pills in his Brave New World classic has been reiterated once and again. And as far as we are concerned this philosophical master piece should continue to be used as a source of inspiration for the much needed public debates on how to proceed with our efforts to explore new territories of chemically intervening in human behaviour and cognition.

Acknowledgements We would like to thank the following colleagues for their comments on preliminary versions of the manuscript: Prof. Dr. Trudy Dehue, Professor of the History of Psychology, Groningen University, The Netherlands, Prof. Dr. Charles Kaplan, Professor and Associate Dean of Research at the University of Houston, College of Social Work and Prof. D. Frans J. Meijman, Professor of Medical Science Communication and its History, VU Amsterdam medical center, The Netherlands.

\section{References}

1. Franzen, Jonathan. 2001. The corrections. London: Fourth Estate.

2. Fukuyama, Francis. 2002. Our posthuman future. London: Profile books.

3. Healy, David. 2004. Let them eat Prozac. New York: New York University Press.

4. Horwitz, Allen V., and Jerome C. Wakefield. 2007. The loss of sadness; How psychiatry transformed normal sorrow into depressive disorder. Oxford: Oxford University Press.

5. Barber, Charles. 2008. Comfortably numb; How psychiatry is medicating a nation. New York: Pantheon books.

6. Moncrieff, Joanna 2008. The myth of the chemical cure; $A$ critique of psychiatric drug treatment. London: Palgrave.

7. Critser, Greg. 2005. Generation Rx; How prescription drugs are altering American lives, minds and bodies. Houghton Mifflin.

8. Dehue, Trudy. 2008. De depressie epidemie. Amsterdam: Augustus.

9. Huxley, Aldous. 1932. Brave new world. New York: Harper and Brothers.

10. Pieters, Toine, and Stephen Snelders. 2005. Mental ills and the hidden history of drug treatment practices. In Psychiatric cultures compared. Psychiatry and mental health care in the twentieth century: Comparisons and approaches, eds. Marijke Gijswijt-Hofstra, Harry Oosterhuis, Joost Vijselaar, and Hugh Freeman, 381-401. Amsterdam: Amsterdam University Press.

11. Snelders, Stephen, Charles Kaplan, and Toine Pieters. 2006. On cannabis, chloral hydrate, and career cycles of psychotropic drugs in medicine. Bulletin of the History of Medicine 80: 95-114.

12. Bourke, Joanna. 2005. Fear; A cultural history. London: Virago.

13. Tomlinson, John. 2007. The culture of speed; The coming of immediacy. London: Sage.

14. Seige, Max. 1912. Klinische Erfahrungen mit Neuronal. Deutsche Medizinische Wochenschrift 38: 1828.

15. Pieters, Toine 2004. Historische trajecten in de farmacie; Medicijnen tussen confectie en maatwerk. Hilversum: Uitgeverij Verloren.

16. Weber, Matthias M. 1999. Die Entwicklung der Psychopharmakologie im Zeitalter der naturwissenschaftlichen Medizin. Ideeengeschichte eines psychiatrischen Therapiesystems. München: Urban \& Vogel.

17. Pieters, Toine, and Stephen Snelders. 2008. Surviving the Seige cycle and managing a double bind: The case of Halcion in the Netherlands. In Ways of regulating: Therapeutic agents between plants, shops and consulting rooms, eds. Gaudilliere, Jeanne-Paul, Volker Hess. MaxPlanck-Institut für Wissenschaftsgeschichte, Preprint 363, Berlin.

18. Shorter, Edward. 1997. A history of psychiatry; From the era of the asylum to the age of Prozac. New York: Wiley.

19. Rasmussen, Nicholas. 2008. On speed; The many lives of amphetamine. New York: New York University Press.

20. Hodgson, Barbara. 2001. In the arms of Morpheus: The tragic history of laudanum, morphine, and patent medicine. New York: Firefly Books. 
21. Davenport-Hines, Richard 2002. The pursuit of oblivion. New York: Norton \&Company.

22. Courtwright, David T. 2001. Forces of habit: Drugs and the making of the modern world. Cambridge: Harvard University Press.

23. Pieters, Toine, and Stephen Snelders. 2007. From King Kong pills to mother's little helpers - career cycles of two families of psychotropic drugs: the barbiturates and benzodiazepines. Canadian Bulletin of Medical History 241: 93-112.

24. Shepard, Ben. 2000. A war of nerves; Soldiers and psychiatrists (1914-1994). London: Cape.

25. Herzberg, David 2009. Happy pills in America; From Miltown to Prozac. Baltimore: The Johns Hopkins University Press.

26. Healy, David. 2002. The creation of psychopharmacology. Cambridge: Harvard University Press.

27. Greene, Jeremy A. 2007. Prescribing by numbers; drugs and the definition of disease. Baltimore: The Johns Hopkins University Press.

28. Lesch, John E. 2007. The first miracle drugs; How the sulfa drugs transformed medicine. Oxford: Oxford University Press.

29. De Kruijf, Paul. 1957. A man against insanity. New York: Grove Press.

30. Swazey, Judith P. 1974. Chlorpromazine in psychiatry; A study of therapeutic innovation. Cambridge (MA): MIT.

31. De Ropp, Robert S 1957. Drugs and the mind. New York: Grove.

32. Campbell, Nancy. D. 2007. Discovering addiction; The science and politics of substance abuse research. Ann Arbor: The University of Michigan.

33. Baenninger, Alex, Jorge A. Costa e Silva, Ian Hindmarch, Hans-Juergen Moeller, and Karl Rickels. 2004. Good chemistry: The life and legacy of valium inventor Leo Sternbach. New York: McGraw Hill.

34. Healy, David. 1997. The Antidepressant Era. Cambridge: Harvard University Press.

35. Tone, Andrea. 2005. Listening to the past: history, psychiatry and anxiety. Canadian Journal of Psychiatry 50: 373-380.

36. Tone, Andrea. 2007. Tranquillizers on trial: Psychopharmacology in the age of anxiety. In Medicating modern
America; Prescription drugs in history, eds. Tone Andrea, and Watkins Elizabeth Siegel, 156-183. New York: New York University Press.

37. Speaker, Susan L. 1997. From "Happiness Pills" to "National Nightmare": changing cultural assessment of minor tranquillizers in America, 1955-1980. Journal of the History of Medicine 52: 338-376.

38. Medawar, Charles. 1992. Power and dependence. London: Social Audit.

39. Pieters, Toine, and Stephen Snelders. 2005. Antidepressiva van 1950 tot heden. Een halve eeuw op chemische wolken. Maandblad voor Geestelijke volksgezondheid 60: 207-222.

40. Grob, Gerald N 1994. The mad among us; A history of the care of America's mentally ill. Cambridge: Harvard University Press.

41. Iversen, Lesley. 2008. Speed > Ecstacy > Ritalin; The science of amphetamines. Oxford: Oxford University Press.

42. Collin, Matthew 1997. Altered State; The story of ecstacy culture and acid house. London: Serpent's Tail.

43. Reynolds, Simon 1999. Generation ecstasy; into the world of the techno and rave culture. New York: Routledge.

44. Shorter, Edward. 2008. Before Prozac: The troubled history of mood disorders in psychiatry. New York: Oxford University Press.

45. Pieters, Toine, and Mineke te Hennepe Mineke de Lange. 2002. Pillen \& Psyche: culturele eb-en vloedbewegingen. Medicamenteus ingrijpen in de psyche. Den Haag: Rathenau Instituutwerkdocument 87.

46. Sahakian Barbara, and Sharon Morein-Zamir. 2007. Professor's little helper. Nature 450: 1157-1159.

47. Gezondheidsraad. 2002. De toekomst van ons zelf. Den Haag: Gezondheidsraad. Publicatie nr. 2002/13.

48. Fukuyama, Francis. 2002. Our posthuman future; Consequences of the biotechnology revolution. London: Profile books.

49. Rose, Nikolas. 2007. The politics of life itself. Princeton: Princeton University Press.

50. Kutchins, Herb, and Stuart A. Kirk. 1997. Making us crazy; DSM-The psychiatric bible and the creation of mental disorders. London: Constable. 